\title{
Strain differences in simple operant barpress acquisition to an auditory stimulus by rats
}

\author{
GORDON M. HARRINGTON \\ University of Northern Iowa, Cedar Falls, Iowa 50613
}

\begin{abstract}
Response rates during operant acquisition of a leverpress to an auditory stimulus with food reinforcement were obtained for 491 rats from 12 inbred strains: ACI, A990, A35322, F344, INR, IR, MNR/Har, MNRA, MR/Har, TS1, TS3, WAG. The results provide parametric data for methodological use and add to the standardization of these strains as behaviorally defined lines.
\end{abstract}

Although the Skinner box has become the principal apparatus for behavioral studies, research on genetic variation in learning in the rat dates back over 50 years (Tolman, 1924). In the interim, the study of behavior genetics developed to the status of a distinct specialty, learning became the central organizing concept in psychology, the rat became the standard infrahuman subject, and the Skinner box became the principal apparatus for animal research in the behavioral laboratory. These circumstances would lead one to expect a substantial volume of studies relating genetic variation in the rat to behavior in this apparatus. It is remarkable that such studies both date to the early use of the apparatus and can be counted on the fingers of one hand (Estes, 1942; Heron \& Skinner, 1939, 1940).

Recent years have seen major methodological developments in other disciplines in precise specification and standardization of laboratory preparations (International Committee on Laboratory Animals, 1971). The present study is one of a number of studies (Harrington, 1971a, 1971b, 1972, 1979a, 1979b, 1979c, 1979d, 1979e, 1979f, 1979g, 1979h; Harrington \& Hellwig, 1979a, 1979b) intended to provide behavioral standardization data on those 12 genetically defined lines of rats having the highest citation frequency in the behavioral literature. Here, strain variations are examined in the most basic of behavioral procedures, simple operant acquisition.

\section{METHOD}

\section{Subjects}

Subjects were 491 rats, aged 114-128 days at time of test, with a minimum of 20 animals of each sex within each of the following 12 inbred strains: ACI/Har, A990/Har, A35322/Har, F344/DuHar, INR, IR, MNR/Har, MNRA (formerly MNR-a/Har), MR/Har, TS1, TS3, and WAG/Har. All lines are designated by the standard nomenclature for this species and are described in the fourth international listing (Festing \& Staats, 1973). Animals were bred and maintained at $25.5^{\circ} \mathrm{C} \pm 1.1^{\circ} \mathrm{C}$ and $40 \% \pm 5 \%$ relative humidity. Breeders and pups were housed under natural light cycle. Pups were handled for $1 \mathrm{~min}$ on alternate days from age 14 to $\mathbf{4 5}$ days. At $\mathbf{4 5}$ days, they were transferred to individual cages with 24-h light cycle. More detailed descriptions are available elsewhere (Harrington, 1968).

\section{Apparatus and Procedure}

All testing was carried out in a Lehigh Valley Electronics rat chamber with 45-mg Noyes pellets as reinforcement. Subjects had been adapted to the chambers for $16-2 / 3 \mathrm{~min} /$ day for 5 days, beginning 28 days prior to experimentation. Fourteen days before experimentation, animals were placed on restricted food and progressively reduced to $85 \%$ of projected ad-lib body weight. On the first day of experimentation, animals were pretrained in three sessions, in each of which they consumed two pellets placed on the bar manipulandum and two pellets from the food reinforcement hopper. Testing was carried out on the succeeding days for 10 daily sessions for $1,000 \mathrm{sec} /$ day. An auditory pure-tone stimulus was presented at the start of each session and at random intervals following reinforcement, with tone offset and reinforcement contingent upon barpress in the presence of the auditory stimulus. Conditioned responses were automatically recorded and filed with a data acquisition and control system. Stimulus pitch and timing of presentations were conventional, but precise details are no longer available because of fire loss of equipment and records.

\section{RESULTS AND DISCUSSION}

The means and standard deviations of numbers of conditioned barpresses over 10 daily sessions are displayed in Table 1. A35322, MNRA, TS3, and WAG lines were all characterized by relatively high acquisition rates, with some other strains at almost the same levels. IR and TS1 were at the other extreme. For experimental designs where subject differentiation on lever operant acquisition might be useful, there would appear to be a relatively wide choice for high-rate animals and two alternatives for low rate.

It is clearly evident from simple inspection of the data that there are substantial strain differences in operant acquisition under these conditions. The importance of operant method together with this evidence of large genetic variation would seem to imply substantial methodological potential in further standardization with respect to conditioning characteristics. 
Table 1

Conditioned Operant Responses to an Auditory Stimulus of 12 Inbred Strains of Rats

\begin{tabular}{lccccc}
\hline & \multicolumn{3}{c}{ Conditioned Responses* } \\
\cline { 2 - 3 } \cline { 5 - 6 } Strain & \multicolumn{2}{c}{ Males } & & Females \\
\cline { 2 - 3 } \cline { 5 - 6 } Mean & SD & & Mean & SD \\
\hline ACI/Har & 27.8 & 38.2 & 75.4 & 56.3 \\
A990/Har & 79.5 & 56.6 & 55.4 & 56.7 \\
A35322/Har & 81.4 & 40.1 & 80.9 & 45.8 \\
F344/DuHar & 48.0 & 55.2 & 54.9 & 57.7 \\
INR & 65.3 & 29.4 & 73.1 & 33.3 \\
IR & 17.4 & 31.6 & 27.1 & 40.1 \\
MNR/Har & 91.3 & 56.4 & 57.5 & 51.5 \\
MNRA & 80.8 & 36.2 & 77.4 & 39.6 \\
MR/Har & 25.0 & 31.2 & 49.2 & 44.6 \\
TS1 & 19.2 & 42.7 & 20.1 & 30.5 \\
TS3 & 73.8 & 48.7 & 76.9 & 42.3 \\
WAG/Har & 86.1 & 47.9 & 71.0 & 34.8 \\
\hline
\end{tabular}

Note $-N \geqslant 20$ for each sex within each strain.

*Barpresses $/ 10$ days for $1,000 \mathrm{sec} /$ day.

\section{REFERENCES}

Estes, W. K. Spontaneous recovery from extinction in mazebright and maze-dull rats. Journal of Comparative Psychology, 1942, 34, 349-351.

Festing, M., \& StaAts, J. Standardized nomenclature for inbred strains of rats. Transplantation, 1973, 16, 221-245.

HARRINGTON, G. M. Genetic-environmental interaction in "intelligence." I: Biometric genetic analysis of maze performance of Rattus Norvegicus. Developmental Psychobiology, 1968, 1, 211-218.

HARRINGton, G. M. Strain differences among rats initiating exploration of differing environments. Psychonomic Science, 1971, 23, 348-349. (a)

HARRINGTON, D. M. Strain differences in rotating wheel activity of the rat. Psychonomic Science, 1971, 23, 363-364. (b)

HARRINGTON, G. M. Strain differences in open field behavior of the rat. Psychonomic Science, 1972, 27, 51-53.

HARRIngton, G. M. Strain differences in activity of the rat in a shuttle stabilimeter. Bulletin of the Psychonomic Society, $1979,13,149.150$. (a)

Harrington, G. M. Strain differences in activity of the rat using a home cage stabilimeter. Bulletin of the Psychonomic Society, 1979, 13, 151-152. (b)

HARRINGTON, G. M. Strain differences in free operant leverpress levels in the rat. Bulletin of the Psychonomic Society, 1979, 13, 153-154. (c)

Harrington, G. M. Strain differences in light-contingent barpress behavior of the rat. Bulletin of the Psychonomic Society, $1979,13,155-156$. (d)

HARRINGton, G. M. Strain differences in open-field behavior of the rat. II. Bulletin of the Psychonomic Society, 1979, 13, 85-86. (e)

HARRINGton, G. M. Strain differences in passive avoidance conditioning in the rat. Bulletin of the Psychonomic Society, 1979, 13, 157-158. (f)

HARRINGTON, G. M. Strain differences in runway learning in the rat. Bulletin of the Psychonomic Society, 1979, 13, 159-160. (g)

HARRINGTON, G. M. Strain differences in shuttle avoidance conditioning in the rat. Bulletin of the Psychonomic Society, 1979, 13, 161-162. (h)

Harrington, G. M., \& Hellwig, L. R. Strain differences in basal metabolism of behaviorally defined rats. Bulletin of the Psychonomic Society, 1979, 13, 165-166. (a)

Harrington, G. M., \& Hellwig, L. R. Strain differences in organ weights of behaviorally defined rats. Bulletin of the Psychonomic Society, 1979, 13, 167-169. (b)

HeRoN, W. T., \& SkINNER, B. F. Rate of extinction in maze bright and maze dull rats. Psychological Bulletin, 1939, 36, 520.

Heron, W. T., \& SkINNER, B. F. The rate of extinction in maze bright and maze dull rats. Psychological Record, 1940, 4, 11-18.

International Committee on Laboratory Animals. Defining the laboratory animal. Washington, D.C: National Academy of Sciences, 1971.

Tolman, E. C. Inheritance of maze learning ability in rats. Journal of Comparative Psychology, 1924, 4, 1-18.

(Received for publication January 3, 1979.) 